\title{
BUILDING THE LIFE MOLECULES: DNA AND RNA
}

\author{
L.M. Beltramini; A.P.U. de Araújo; L.D.S. Abel; J.C.Q. Carvalho; *O.H.P. Ramos; T.H.G. Oliveira; F. \\ Moron; N.F. dos Santos
}

Centro de Biotecnol. Molecular Estrutural (CBME)- IFSC - USP; *Dep. de Ciências Fisiológicas - UFSCar São Carlos - Brasil

The dissemination area of the Centro de Biotecnologia Molecular Estrutural (CBME) have been developing a program of new tools to help teaching and learning of structural molecular biology area at all levels, from elementary to graduate schools. In this way, we have developed a kit denoted Building the life molecules: DNA and RNA. The kit is composed by: (1) an interactive software called The Virtual Cells, used to facilitate the comprehension of the structures and functions of different types of cells; (2) several small plastic elements with proper flexibility that allows building DNA and RNA structure models; (3)an Amino Acid Disk, with the amino acids structures, their abbreviation and the genetic code; (4) a folder containing a historical about events on DNA discovery and instruction to used the tools. These tools contribute to the understanding of the cell structure, its different organelles and functions, specially the organization of the nucleus, nucleic acids and genetic code. The plastic elements and Amino Acid Disk permit the students to understand DNA and RNA molecule structure, as well as the semi conservative duplication of DNA, the transcription and translation processes. Such plastic components emphasize chemical connections and respect the real molecular structure parameters keeping size proportionality. The Amino Acid Disk is composed by superposed rotating disks, with openings allowing information on the amino acids can be observed. In the opposite face contents a genetic code table. With this tool, teachers and students are able to simulate the synthesis of a given protein, after assembling the structure of RNAm and perceiving the molecular dynamic. The historical about events on DNA discovery helps one to better understand the development of science. We have evaluated this kit and its usefulness in learning. The data demonstrated it has high didactic potential since of its easy handling. The development of this kit is part of a broad diffusion project of scientific knowledge, which CBME performs with the purpose of providing, in a playful way, the comprehension of the structure-function paradigm of biological macromolecules. CEPID/FAPESP 